\title{
Difficulty in Central Venous Cannulation due to Kinked Guidewire: Intravenous Cannula Comes to Rescue!
}

\author{
Ritesh Lamsal $^{1} \quad$ Surya Kumar Dube ${ }^{1} \quad$ Ashish Bindra $^{1}$
}

Address for correspondence Surya Kumar Dube, MD, DM, Department of Neuroanaesthesiology and Critical Care, 7th Floor, Neurosciences Center, All India Institute of Medical Sciences, New Delhi 110029, India (e-mail: surya.dube@yahoo.co.in).

In our case, probably owing to the pressure applied while railroading the CVC over the guidewire, the soft and fragile guidewire got kinked preventing the advancement of the CVC further. In that situation, current practice advocates removal of the guidewire and reattempting CVC. However, we tried CVC insertion using a 22G IV cannula (-Fig. 1B), because we were not able to insert the guidewire into IJV. It was probably due to displacement of introducer needle (after localization of vein), either before or during insertion of J-tip guidewire. This can happen during pediatric CVC insertion. ${ }^{3}$ Finally, when we inserted the guidewire into the IJV, it got kinked while railroading the CVC. Hence, reattempting CVC insertion might not have solved the problem and would have led to another puncture, thereby increasing the risk of further CVC insertion-related complications. Use of IV cannula for ease of CVC insertion in pediatric patients has been reported previously. ${ }^{3,4}$ In our case, being soft and flexible, the IV cannula sheath could be easily threaded over the kinked portion of the guidewire into the central vein. Later, the sheath acted as a conduit for insertion of a new guidewire.

With this report, we suggest use of IV cannula for exchanging kinked guidewire during difficult CVC insertion in pediatric patients.

\section{Funding}

None.

\section{Conflict of Interest}

None. easily. The child did not have any CVC insertion-related complication in the postoperative period.
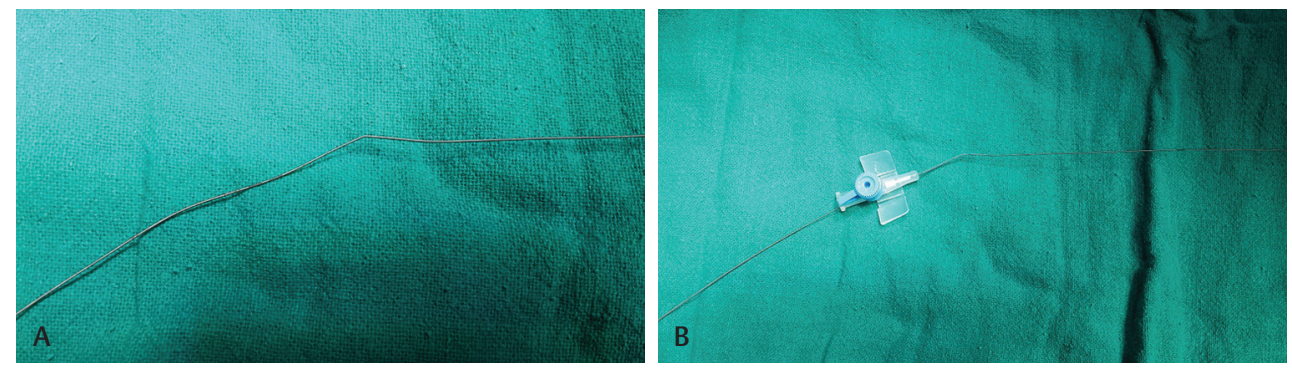

Fig. 1 (A) Kinked guidewire. (B) Guidewire inside a 22G intravenous catheter.

received

February 23, 2018

accepted

April 16, 2018

published online

May 18, 2018
DOI https://doi.org/

10.1055/s-0038-1655900. ISSN 2348-0548.
Copyright $\odot 2018$ Indian Society of Neuroanaesthesiology and Critical Care
License terms

(1) (1) $\Theta \circledast$ 


\section{References}

1 Stenzel JP, Green TP, Fuhrman BP, Carlson PE, Marchessault RP. Percutaneous central venous catheterization in a pediatric intensive care unit: a survival analysis of complications. Crit Care Med 1989;17(10):984-988

2 Sheridan RL, Weber JM. Mechanical and infectious complications of central venous cannulation in children: lessons learned from a 10-year experience placing more than 1000 catheters. J Burn Care Res 2006;27(5):713-718

3 Dube SK, Chaturvedi A. A simple technique to avoid difficulty in guide wire insertion during pediatric central venous cannulation. Saudi J Anaesth 2014;8(1):141-142

4 Nakayama S, Takahashi S, Toyooka H. Curved-end guidewire for central venous cannulation in neonate. Anesth Analg 2003;97(3):917-918 